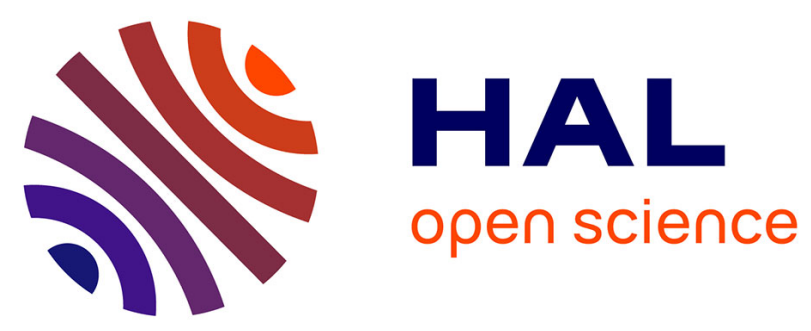

\title{
Why the viability of spermatozoa diminishes in the honeybee (Apis mellifera) within short time during natural mating and preparation for instrumental insemination
}

H. Gençer, Yasin Kahya, Jerzy Woyke

\section{To cite this version:}

H. Gençer, Yasin Kahya, Jerzy Woyke. Why the viability of spermatozoa diminishes in the honeybee (Apis mellifera) within short time during natural mating and preparation for instrumental insemination. Apidologie, 2014, 45 (6), pp.757-770. 10.1007/s13592-014-0295-0 . hal-01234777

\author{
HAL Id: hal-01234777 \\ https://hal.science/hal-01234777
}

Submitted on 27 Nov 2015

HAL is a multi-disciplinary open access archive for the deposit and dissemination of scientific research documents, whether they are published or not. The documents may come from teaching and research institutions in France or abroad, or from public or private research centers.
L'archive ouverte pluridisciplinaire HAL, est destinée au dépôt et à la diffusion de documents scientifiques de niveau recherche, publiés ou non, émanant des établissements d'enseignement et de recherche français ou étrangers, des laboratoires publics ou privés. 


\title{
Why the viability of spermatozoa diminishes in the honeybee (Apis mellifera) within short time during natural mating and preparation for instrumental insemination
}

\author{
H. Vasfi GENÇER ${ }^{1}$, Yasin KAHYA ${ }^{1}$, Jerzy WOYKE ${ }^{2}$ \\ ${ }^{1}$ Faculty of Agriculture, Department of Animal Science, Ankara University, 06110, Ankara, Turkey \\ ${ }^{2}$ Apiculture Division, University of Life Sciences-SGGW, 166 Nowoursynowska, 02-787, Warsaw, Poland
}

Received 30 November 2013 - Revised 2 May 2014 - Accepted 7 May 2014

\begin{abstract}
The viability of spermatozoa is a crucial parameter to appreciate semen quality and insemination potential of males both in natural mating and instrumental insemination. Here, we conducted a step-by-step investigation to address the questions why and at which step(s) the viability loss is occurring in spermatozoa of honeybees during natural mating and preparation for instrumental insemination. We detected the viability of spermatozoa in semen samples obtained from seminal vesicles and partly and fully everted endophalli of drones and in ejaculates collected into syringe tips, as well as the viability of spermatozoa in lateral oviducts of queens returning from the mating flight. A great diminish of spermatozoa viability $(\sim 10 \%)$ was found in lateral oviducts of queens returning from mating flight $(88.7 \%)$ in comparison to viable spermatozoa in intact seminal vesicles of drones $(98.1 \%)$. Our results demonstrated that the decrease in spermatozoa viability occurs during the second stage of eversion of endophallus (viability loss, $3.3 \%$ ), and during injection of semen into the lateral oviducts of queens (viability loss, $6.1 \%$ ). The acting factor decreasing the viability of spermatozoa was the increased pressure occurring during the process of natural and instrumental insemination.
\end{abstract}

drone / queen / Apis mellifera / eversion of endophallus / spermatozoa viability / instrumental insemination

\section{INTRODUCTION}

Among livestock, the honeybee (Apis mellifera L.) is unique with respect to reproductive features. Highly polyandrous queens mate with 6-18 drones in one or more nuptial flights when they are about 4-6 days old, prior to egg laying (Taber 1954; Peer 1956; Woyke 1956). During subsequent copulations in the air, semen from each drone is ejaculated forcefully into the vagina and lateral oviducts of the queen

Corresponding author: H. V. Gençer, gencer@agri.ankara.edu.tr Manuscript editor: James Nieh
(Woyke 1956, 2008, 2010, 2011; Koeniger et al. 1979). The ejaculates are pressed and probably mixed in greatly expanded lateral oviducts by both subsequent explosive ejaculations of drones (Woyke 2008) and muscular contractions of the reproductive tract of the queen (Page 1986) before the migration of spermatozoa into spermatheca. The queen returns to the hive after mating, with an average of $11.5 \mu \mathrm{L}$ semen in her lateral oviducts and about 100 million spermatozoa in entire genital tract (Woyke 1962). Spermatozoa are transferred gradually into the spermatheca (Woyke 1983, 1988) by a combination of spermatozoa activity, abdominal contractions of the queen, and by the pump of the spermathecal duct, as well as the activity of 
spermathecal fluids and glands (Ruttner and Koeniger 1971). The whole process requires about a period of 10-20 h (Woyke 1962). During the migration and storage process, excess spermatozoa are discharged from the lateral oviducts through the vagina. At the end, only $5 \%$ of all spermatozoa are permanently stored in the spermatheca (Woyke 1962; Koeniger and Koeniger 1991). A lifetime stock of spermatozoa in the spermatheca remains viable for several years (Verma 1974). In adult drones, the spermatozoa are present in the seminal vesicles (Figure 1). The bulb of the endophallus (blb) is empty. It becomes filled during the mating flight.

Natural mating occurs in the open air. Films of Koeniger (n.d.) and of Imhoof (2012) present this phenomenon. During mating, eversion of the endophallus occurs at two steps, as partial eversion and full eversion. Initially, the vestibulum and cornua are everted (partial eversion, Figure 2). At partial eversion, the empty bulb of the endophallus is pushed inside the everted vestibulum, and then, the bulb is filled with semen and mucus. Partial eversion of the endophallus stops with the cervical duct at the end (Woyke 2008). When the drone mounts the queen from behind, he inserts the cervical duct of the endophallus into the vaginal orifice of the queen, after the queen has opened her sting chamber (Koeniger 1986; Woyke 2008). Since the bulb of the endophallus cannot pass through the narrow cervical duct, the eversion stops for a short break (Woyke 2008). At that time, the drone is already paralyzed and becomes motionless (Koeniger 1986). When the pressure inside the partly everted endophallus is increased sufficiently, the dorsal walls of the duct are opened, and the bulb passes through it, which results in full eversion (Woyke 2008). The increased pressure inside the endophallus injects the semen with great force through the small vaginal orifice of the queen and then into the lateral oviducts (Figure 3 ). The ejaculation of semen under great force is especially important during multiple matings, because the oviducts already contain semen from previous matings (Woyke 2008).

The viability of spermatozoa is a crucial parameter to appreciate reproductive success of males. Hunter and Birkhead (2002) found that the males of polyandrous insect species have a higher proportion of live spermatozoa in their seminal vesicles, compared to monandrous sister species. This suggests that spermatozoa viability is important in species where males

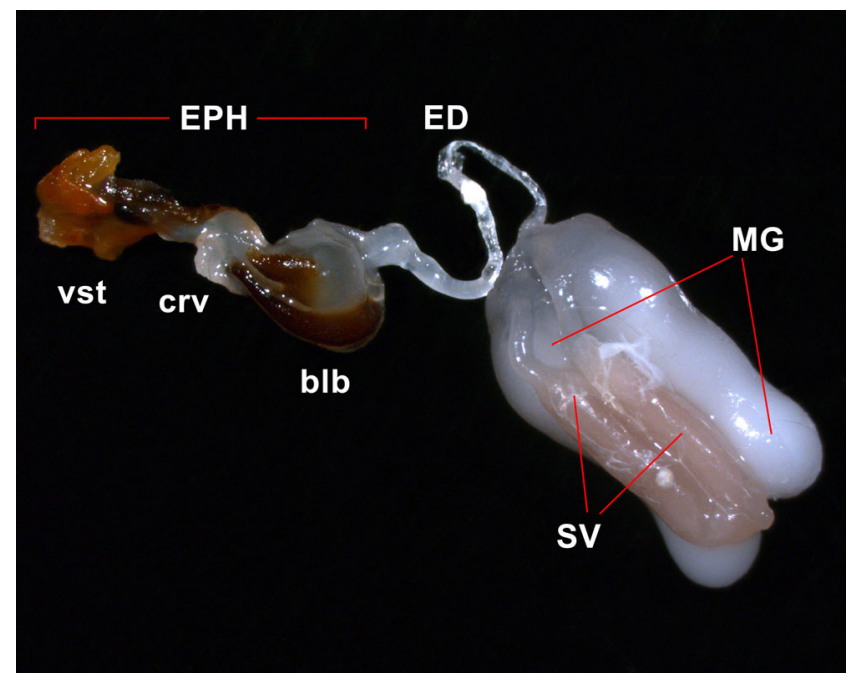

Figure 1 Reproductive organs of a drone. EPH endophallus, blb bulb, crv cervix, vst vestibulum, ED ejaculatory duct, $M G$ mucus glands, $S V$ seminal vesicles. Testes were removed. 


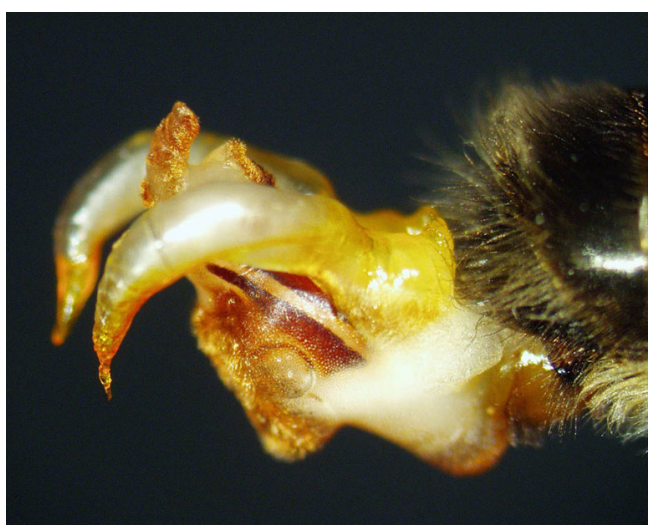

Figure 2 Partly everted endophallus.

compete for egg fertilization. Reproductive success of males is correlated with both the quantity (Schlüns et al. 2004) and quality of spermatozoa (Hunter and Birkhead 2002). Therefore, spermatozoa viability should be maintained at a high level throughout the mating and spermatozoa storage process (den Boer et al. 2009). Especially important is the fact that the spermatozoa after entering into the spermatheca of honeybee queens must survive for several years. According to Collins (2000, 2004), a honeybee queen with low viability of spermatozoa in her spermatheca will be expect- ed to become a drone layer more quickly than usual.

Several authors reported factors affecting spermatozoa viability in drones such as miticide application during pupal development (Burley et al. 2008), different temperature regimes during pupal development (Czekońska et al. 2013a) and during sexual maturation (Stürup et al. 2013), senescence (Locke and Peng 1993; Baer et al. 2012; Czekońska et al. 2013b; Stürup et al. 2013), etc. Different methods applied and conditions during semen collection procedure (Collins 2003, 2004; Bieńkowska et al. 2011) and in vitro semen storage conditions (Collins 2000; Burley et al. 2008; Hopkins and Herr 2010; Wegener and Bienefeld 2012; Wegener et al. 2012) are also significant factors influencing spermatozoa viability.

Gençer and Kahya (2011a) previously demonstrated that spermatozoa in seminal vesicles of drones reared in optimal conditions were remarkable for viability (98\%). However, the viability of spermatozoa in the lateral oviducts of queens at $4 \mathrm{~h}$ after they were either naturally mated or instrumentally inseminated (87.6 and 88.6 \%, respectively; Gençer and Kahya 2011b) were lower than the viability of spermatozoa in seminal vesicles of drones (98\%; Gençer and Kahya 2011a). Accordingly, we thought that

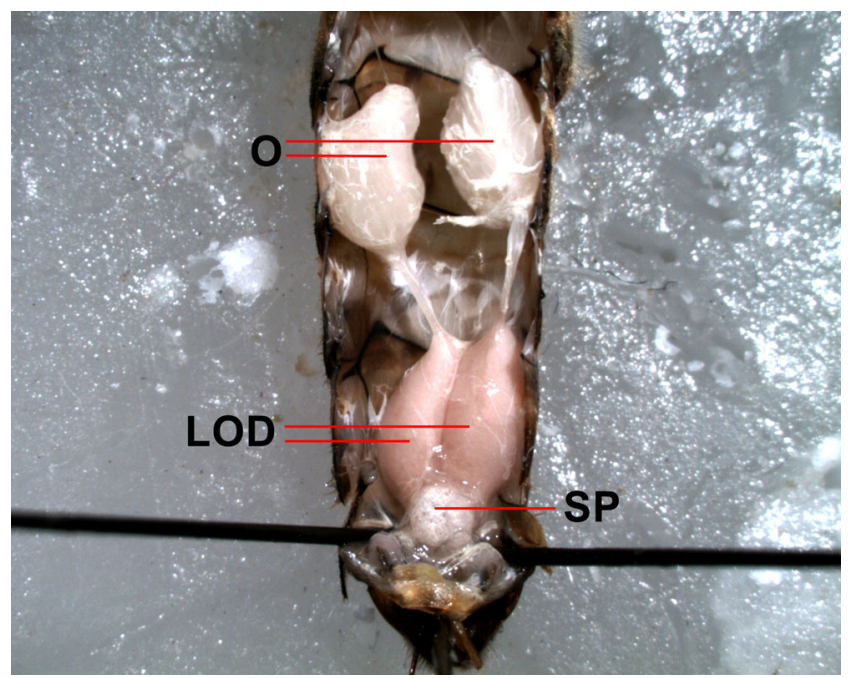

Figure 3 Reproductive organs of a mated queen. $L O D$ lateral oviducts filled with semen, $O$ ovaries, $S P$ spermatheca. 
there must be viability loss during eversion and ejaculation and/or the mating process. Little is known about spermatozoa viability in drones and queens during mating and spermatozoa storage process. We conducted the present study to clarify why and at which step(s) viability loss is occurring within short time during natural mating and instrumental insemination. To do so, we detected spermatozoa viability in semen samples obtained from seminal vesicles and partly and fully everted endophalli of drones and in ejaculates collected into the syringe tip, as well as the spermatozoa viability in lateral oviducts of queens returning from mating flight.

\section{MATERIAL AND METHODS}

\subsection{Drone and queen rearing}

The honeybee colonies at Ankara University, Turkey were used to rear experimental drones and queens in the summer of 2013. All colonies in the apiary were treated against Varroa destructor in March 2013. Ten equal-sized colonies headed by sister queens were selected as drone rearing colonies. A drone comb was introduced into the middle of the brood area of each colony. The queen in each colony was confined on drone comb in a queen excluder cage within the hive. When the queens uniformly laid unfertilized eggs on both sides of drone combs, the queens were released, while drone brood combs were left for development. One day before emergence, drone brood combs were again installed into queen excluder cages to prevent emerging drones from dispersing in the hives. After 1 day, the adult drones that emerged from brood combs within 1 day were marked on the thorax with paint (Edding 751) to obtain drones of known age for measurements. The marked drones were immediately given back to their parent colonies for sexual maturation, and they were allowed to fly freely from their hives. When the drones were older than 2 weeks, they were used for spermatozoa viability tests. The drones of this age were used, as older drones are ready for eversion and ejaculation than younger ones when manually provoked.

A batch of sister queens were reared from a breeder colony by grafting method (Laidlaw and Page 1997). Twenty queen cell cups were introduced into trapezoid Kirchain polystyrene mating nuclei (Ruttner 1988) 1 day before emergence of queens. The queens that emerged in mating nuclei were kept for controlled natural mating flight. The flight entrances of mating nuclei were closed with queen excluder to prevent the queens from uncontrolled flying.

\subsection{Sample preparations for spermatozoa viability analyses}

We conducted our study step-by-step in order to disclose why spermatozoa viability loss is occurring during eversion and ejaculation in mating process and/or during semen collection procedure for instrumental insemination. Fifteen drones captured randomly from the drone source colonies were used for each experimental step except for the test of multipledrone semen $(8 \mu \mathrm{L})$ collected into syringe tip $(8-10$ drones for each $8 \mu \mathrm{L}$ semen sample).

In order to standardize the procedures and to prevent differences in spermatozoa death between treatments due to methodology, many preliminary tests were performed before conducting this study. Several mechanical factors were tested that could affect viability (e.g., the buffer composition, the effect of pipetting, the size of syringe tip, etc.), so that the effects of these factors could be ruled out in the current experiment. As different volumes of semen are dissected from different organs, the dilution factor of semen in buffer might differ, which could in turn influence viability (Holman 2009). However, a preliminary test showed that dilution factor does not affect the viability of spermatozoa (the mean \pm S.E. of spermatozoa viability in ejaculate diluted in $150 \mu \mathrm{L}$ buffer and $300 \mu \mathrm{L}$ buffer, $93.8 \pm$ $0.52 \%$ and $94.4 \pm 0.29 \%$, respectively; Student's $t$ test, two-tailed $\alpha=0.05 ; n=20, F=7.057$, d.f. $=18$, $P=0.323$ ).

\section{Step 1: Semen in seminal vesicles}

This first step was performed to examine the spermatozoa viability in the intact seminal vesicles of the drones reared in optimal conditions. Each drone was dissected (Dade 1977) carefully with a pair of dissection scissors (Hammacher, Solingen) and two watchmaker forceps (Dumont, No. 5) under a macroscope (Leica Z16 APO). 
The intact seminal vesicles were taken out with forceps and then washed with a drop of modified Kiev buffer to prevent semen from contamination by hemolymph. The seminal vesicles were placed in a sterile watch glass (diameter $=6.5 \mathrm{~cm})$ containing $200 \mu \mathrm{L}$ modified Kiev buffer (Moritz 1984). The semen in each seminal vesicle was released by grasping its one end with one of the forceps while compressing it gently through the other end by the tips of the other forceps in modified Kiev buffer. After emptied seminal vesicles were discarded, the released semen was dispersed by shaking the watch glass gently with hand. Then, $150 \mu \mathrm{L}$ of diluted semen was transferred from the watch glass into a sterile microcentrifuge tube $(1.6 \mathrm{~mL})$ by a $200 \mu \mathrm{L}$ micropipette for spermatozoa viability test.

\section{Step 2: Semen in lateral oviducts of naturally mated queen}

In this step, we aimed to determine the viability of spermatozoa in lateral oviducts of queens, as soon as they returned from natural mating. When the queens were 6 days old, the flight entrances of the mating nuclei were opened, and the flights of 15 queens were observed by inspecting mating nuclei at 5-min intervals between 14.00 and $18.00 \mathrm{~h}$. When a queen was detected in mating nucleus with mating sign, she was taken to the laboratory for dissection. Each queen was dissected (Dade 1977) carefully under a macroscope (Leica Z16 APO). The live queen was fastened onto the glass petri dish filled with paraffin by insect pins. The cuticle was then removed by cutting both sides of the abdomen (Figure 3). The lateral oviducts were carefully taken out with forceps and washed with a drop of modified Kiev buffer to prevent contamination by hemolymph. The lateral oviducts of each queen were then placed in a sterile watch glass containing $550 \mu \mathrm{L}$ modified Kiev buffer. The semen in each lateral oviduct was released by grasping it with one of the forceps while tearing its membrane gently with other forceps in modified Kiev buffer. The emptied lateral oviducts were discarded. The released semen in buffer was dispersed by shaking the watch glass gently with hand. Then, $500 \mu \mathrm{L}$ of diluted semen was transferred from the watch glass into a sterile microcentrifuge tube $(1.6 \mathrm{~mL})$ by a $1,000 \mu \mathrm{L}$ micropipette for spermatozoa viability test.

Step 3: Semen in bulb of partly everted endophallus

In this step, our aim was to detect if there was any spermatozoa viability loss during the partial eversion of the endophallus. Each drone was manually provoked by applying pressure on the head and thorax by fingers until the partly everted endophallus appeared (Figure 2). In the meantime, the bulb became filled with semen and mucus. Then, the filled bulb was carefully taken out of the vestibulum by pulling the slender cervical duct at the end of partly everted endophallus with forceps (Figures 4-5). The intact bulb was washed with a drop of modified Kiev buffer and placed in a sterile watch glass containing $200 \mu \mathrm{L}$ modified Kiev buffer. Next, the semen in the bulb was released by tearing the membrane of the bulb with the tips of forceps in modified Kiev buffer (Figure 6). The emptied bulb and mucus particles were discarded. Then, the released semen was processed for spermatozoa viability assay as explained in step 1.

Step 4: Ejaculated semen on fully everted endophallus

In this step, we detected spermatozoa viability loss during the second stage of eversion (full eversion). At first, each drone was manually provoked for the partial eversion. Then, the abdomen of the drone was gently squeezed until the full eversion occurred. As soon as the mucus and semen appeared on the bulb, the fully everted endophallus was immersed into a sterile microcentrifuge tube $(0.6 \mathrm{~mL})$ filled with modified Kiev buffer. The semen on the bulb was released as a dissolving bundle by moving the endophallus slightly in the microcentrifuge tube. Then, excess buffer was taken from the microcentrifuge tube by a micropipette without touching the semen bundle. The semen bundle in $300 \mu \mathrm{L}$ remaining buffer was dispersed by shaking the microcentrifuge tube gently with hand to prepare semen sample for spermatozoa viability assay. 


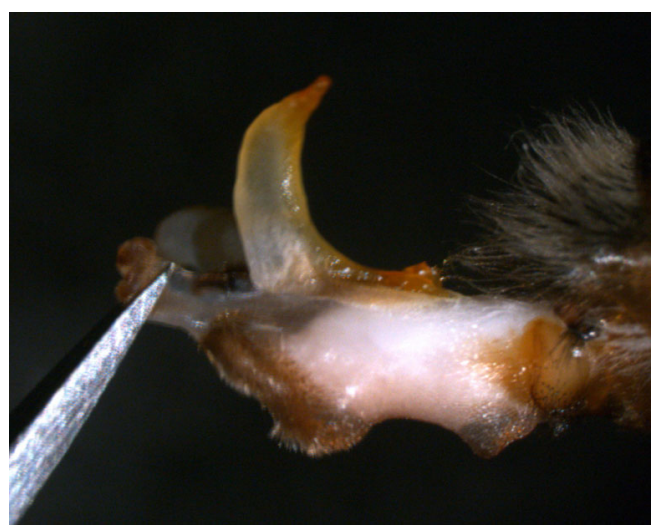

Figure 4 Grasping the slender tip (cervical duct) at the end of partly everted endophallus.

Step 5, 6, and 7: Ejaculated semen on fully everted endophallus exposed to 1, 2, and 4 min aeration

We tested how long aeration (waiting) result in spermatozoa viability loss in ejaculate on the bulb of the endophallus. To test the effect of aeration during semen collection for instrumental insemination, the drones with fully everted endophallus were exposed to air by waiting 1 min (step 5), 2 min (step 6), and 4 min (step $7)$, respectively. When required time $(1,2$, or $4 \mathrm{~min}$ ) was finished, the semen from fully everted endophallus of each drone was processed as explained in previous test (step 4) to prepare the samples for spermatozoa viability assay.

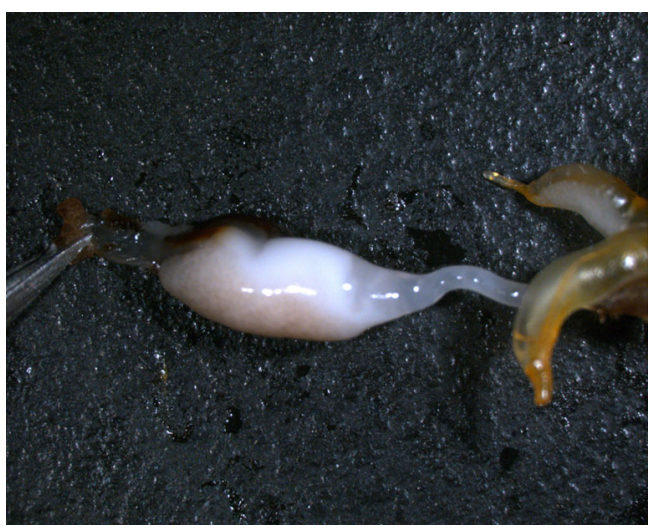

Figure 5 Pulling the slender tip (cervical duct) at the end of partly everted endophallus.

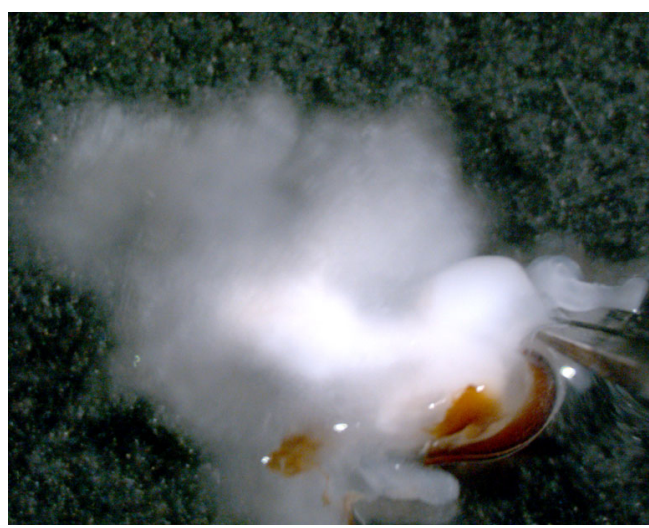

Figure 6 Releasing the semen from the bulb.

Step 8: Semen ejaculated into buffer-filled microcentrifuge tube

In this test, we tried to simulate natural mating condition during eversion of the endophallus and ejaculation to detect further whether air exposure affects sperm viability or not. First, each drone was manually provoked for partial eversion. Then, to prevent a drone from ejaculating in the air, the partly everted endophallus of the drone was inserted into a sterile microcentrifuge tube $(0.6 \mathrm{~mL})$ filled completely with modified Kiev buffer. Both sides of the abdomen were gently squeezed until the second stage of eversion and ejaculation occurred in the buffer-filled microcentrifuge

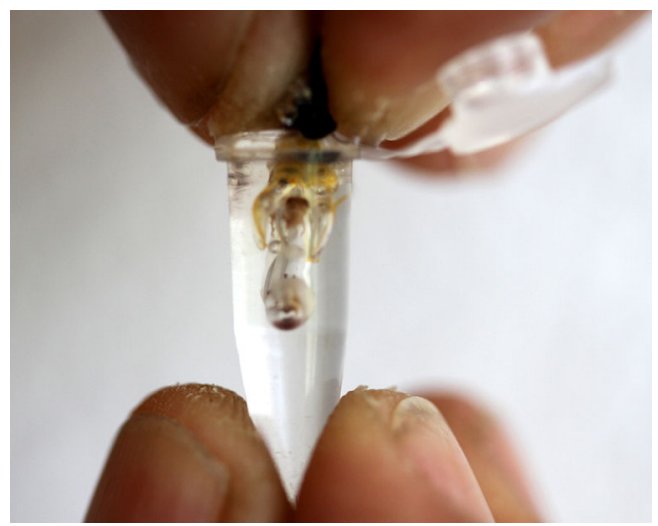

Figure 7 Full eversion and ejaculation in microcentrifuge tube. 
tube (Figure 7). When the semen was released as a dissolving bundle in the microcentrifuge tube, excess buffer was withdrawn by micropipette without touching the semen bundle. Then, the semen bundle was dispersed in $300 \mu \mathrm{L}$ remaining buffer as explained in previous test (step 4) to prepare the sample for spermatozoa viability assay.

Step 9: Hemolymph-added semen ejaculated on fully everted endophallus

The aim in this step was to test whether hemolymph contamination during ejaculation affects spermatozoa viability or not. To test hemolymph effect, two drones were manually provoked for partial eversion in succession. The first drone remained in partly everted state, while the second one was manually forced to full eversion. One of the cornua of the partly everted endophallus of the first drone was cut from the tip by dissection scissors (Figure 8) to release the clear hemolymph as a drop from the stretched vestibulum. Then, the hemolymph drop from the partly everted endophallus of the first drone was dropped on the semen on fully everted endophallus of the second drone (Figure 9). After $1 \mathrm{~min}$ of waiting, hemolymph contaminated semen from the endophallus of the second drone was prepared for spermatozoa viability assay as explained in previous test (step 4).

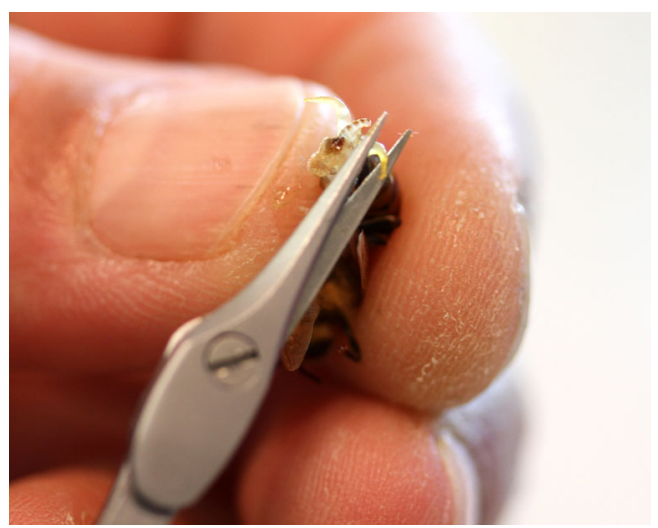

Figure 8 Cutting the tip of one of the cornua of a partly everted endophallus.

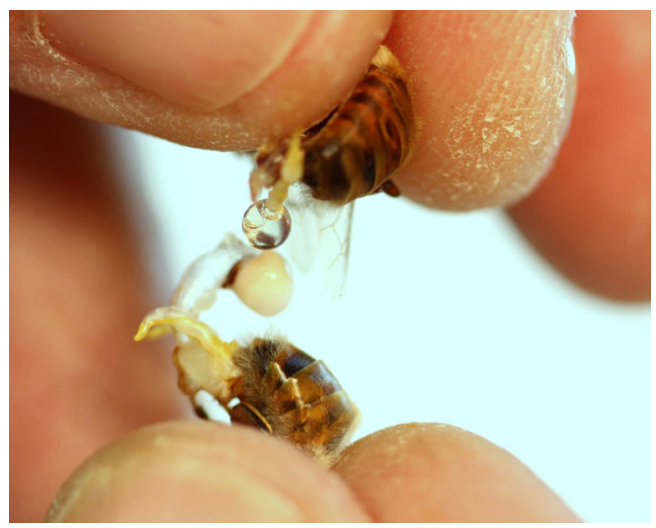

Figure 9 Dropping one drone's hemolymph to the other drone's semen on fully everted endophallus.

Step 10: Single-drone semen collected into the glass tip of syringe

This step was performed to determine the spermatozoa viability in single-drone semen collected into the glass tip of syringe. The semen was collected from fully everted endophallus of one drone into the glass tip of Schley syringe. Then, about $1 \mu \mathrm{L}$ semen was discharged slowly into a sterile microcentrifuge tube $(1.6 \mathrm{~mL})$ filled with $150 \mu \mathrm{L}$ modified Kiev buffer. The semen bundle in $150 \mu \mathrm{L}$ buffer was dispersed by shaking the microcentrifuge tube gently with hand to prepare the sample for spermatozoa viability assay.

Step 11: Multiple-drone semen collected into the glass tip of syringe

To determine the effect of conventional semen collection procedure from multiple drones on spermatozoa viability, $8 \mu \mathrm{L}$ semen (one dose) was collected from fully everted endophalli of 8-10 drones into the glass tip of Schley syringe. Then, $8 \mu \mathrm{L}$ semen in the glass tip was discharged slowly into a sterile microcentrifuge tube $(1.6 \mathrm{~mL})$ filled with $1,200 \mu \mathrm{L}$ modified Kiev buffer. The $8 \mu \mathrm{L}$ semen bundle in $1,200 \mu \mathrm{L}$ buffer was processed as in previous step 10 for spermatozoa viability assay. 
Step 12: Pressure-exposed semen in the bulb of partly everted endophallus

In this step, the aim was to detect if the pressure causes spermatozoa viability loss during the second stage of eversion. Each drone was manually provoked to the partial eversion by pressure on the head and thorax. When the partial eversion occurred, the slender tip of the partly everted endophallus was tightly grasped with a pair of forceps by the one hand (Figure 10). Then, both sides of abdomen were squeezed with increasing pressure by the thumb and forefinger of the other hand (Figure 10) until the bulb that was filled with semen and mucus-epithelium protruded from the stretched vestibulum. Hereafter, semen- and mucus-filled bulb of each drone was processed as explained in previous test (step 3) to prepare semen sample for spermatozoa viability assay.

\subsection{Spermatozoa viability assay}

The viability of spermatozoa in the organs (seminal vesicles, endophalli and lateral oviducts) and in the collected semen samples was determined using LIVE/ DEAD Sperm Viability Kit (L-7011, Molecular Probes) by the LIVE/DEAD dual florescent staining method (Collins and Donoghue 1999). Before use, SYBR-14 and propidium iodide stock solutions were diluted with DMSO (1:50) and distilled water (1:4), respectively. Then, the diluted SYBR-14 and the diluted propidium iodide were added to each semen sample in the

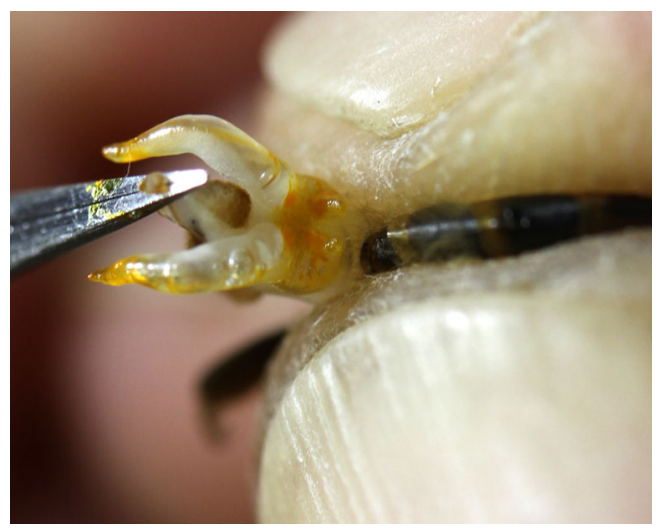

Figure 10 Applying manual pressure on partly everted endophallus without permitting the full eversion. microcentrifuge tube. In steps $1,3,10$, and 12, $0.75 \mu \mathrm{L}$ diluted SYBR-14 and $0.75 \mu \mathrm{L}$ diluted propidium iodide were added to each sample, while $1.25 \mu \mathrm{L}$ diluted SYBR-14 and $1.25 \mu \mathrm{L}$ diluted propidium iodide were added to the samples in steps $4,5,6,7,8$, and 9. In step 2, $2.5 \mu \mathrm{L}$ diluted SYBR-14 and $2.5 \mu \mathrm{L}$ diluted propidium iodide were added to each diluted lateral oviduct content, and in step 11, $6 \mu \mathrm{L}$ diluted SYBR-14 and $6 \mu \mathrm{L}$ diluted propidium iodide were added to each multiple-drone semen content in the microcentrifuge tube.

Each diluted semen sample in microcentrifuge tube was incubated at $36^{\circ} \mathrm{C}$ for $10 \mathrm{~min}$. After incubation, one drop aliquot $(6 \mu \mathrm{L})$ of the stained sample was placed on a glass slide, covered with a cover slip $(24 \times 24 \mathrm{~mm})$ and observed under the laboratory microscope (Leica DM3000) equipped with a fluorescent light source and filters (blue excitation filter cube, I3 and green excitation filter cube, N21) at $\times 400$ magnification. The spermatozoa in six aliquots of each sample were scored as green (live) or red (dead). At least 400 spermatozoa for each sample were counted to determine spermatozoa viability, which was defined as the percentage of the number of live spermatozoa to the total spermatozoa counted. About 72,000 spermatozoa $(12 \times 15 \times 400)$ were counted altogether.

\subsection{Statistical analysis}

The data were analyzed by one-way ANOVA. Data on the spermatozoa viability (\%) was normalized by arc sine transformation before ANOVA. Statistical analyses were performed by IBM SPSS Statistics v. 20 software package.

\section{RESULTS}

Significant differences were found between the spermatozoa viability means of the experimental steps $\left(\mathrm{F}_{11}, 168=50.629, P<0.0001\right.$; Table I). As predicted, the highest proportion of viable spermatozoa $(98.1 \%)$ was found in the intact seminal vesicles of the drones (step 1), whereas the mean spermatozoa viability in the lateral oviducts of the queens which returned from mating flight (step 2) was $88.7 \%$, indicating about $10 \%$ spermatozoa viability loss. 
Table I. Comparisons of sperm viability means (\%) of 15 samples from different sources and procedures.

\begin{tabular}{|c|c|c|c|c|c|}
\hline $\begin{array}{l}\text { Step } \\
\text { (group) }\end{array}$ & Semen sources and procedures & $\begin{array}{l}\text { Mean } \\
(\%)\end{array}$ & S.E. & Minimum & Maximum \\
\hline 1 & Semen in the seminal vesicles & $98.1 \mathrm{a}$ & 0.18 & 96.4 & 99.1 \\
\hline 2 & Semen in the lateral oviducts of naturally mated queen & 88.7 ef & 0.84 & 80.7 & 92.8 \\
\hline 3 & Semen in the bulb of partly everted endophallus & 97.7 a & 0.20 & 96.2 & 99.0 \\
\hline 4 & Ejaculate on fully everted endophallus & $94.8 \mathrm{bc}$ & 0.26 & 92.9 & 96.2 \\
\hline 5 & Ejaculate on fully everted endophallus ( 1 min aeration) & $94.6 \mathrm{bc}$ & 0.27 & 92.7 & 96.0 \\
\hline 6 & Ejaculate on fully everted endophallus ( 2 min aeration) & $91.5 \mathrm{~d}$ & 0.37 & 88.9 & 94.5 \\
\hline 7 & Ejaculate on fully everted endophallus (4 min aeration) & 89.2 ef & 0.65 & 86.0 & 93.3 \\
\hline 8 & $\begin{array}{l}\text { Semen ejaculated into buffer-filled microcentrifuge } \\
\text { tube }\end{array}$ & $94.9 \mathrm{~b}$ & 0.50 & 91.1 & 98.7 \\
\hline 9 & $\begin{array}{l}\text { Ejaculate with hemolymph on fully everted } \\
\text { endophallus }\end{array}$ & $93.4 \mathrm{c}$ & 0.43 & 91.0 & 96.3 \\
\hline 10 & $\begin{array}{l}\text { Single-drone semen }(1 \mu \mathrm{L}) \text { collected into the glass } \\
\text { tip of syringe }\end{array}$ & $88.5 \mathrm{ef}$ & 0.71 & 84.0 & 93.0 \\
\hline 11 & $\begin{array}{l}\text { Multiple-drone semen }(8 \mu \mathrm{L}) \text { collected into the glass } \\
\text { tip of syringe }\end{array}$ & $89.7 \mathrm{e}$ & 0.49 & 86.6 & 93.7 \\
\hline 12 & $\begin{array}{l}\text { Pressure-exposed semen in the bulb of partly everted } \\
\text { endophallus }\end{array}$ & $87.0 \mathrm{f}$ & 1.31 & 79.7 & 94.9 \\
\hline
\end{tabular}

Different letters denote significant differences between means.

\subsection{Pressure effect}

The viability of spermatozoa in the bulb of partly everted endophallus ( $97.7 \%$; step 3 ) was not found to differ significantly from that of spermatozoa in the intact seminal vesicles (98.1\%; Table I, step 1). No significant spermatozoa viability loss $(0.4 \%)$ was detected during the partial eversion of the endophallus. But, significant spermatozoa viability loss occurred, when the eversion was completed. The spermatozoa viability diminished significantly from $98.1 \%$ (step 1) to $94.8 \%$ (step 4 ; viability loss, $3.3 \%$ ). When the semen in the bulb of the partly everted endophallus was artificially exposed to additional pressure (step 12), the viability diminished significantly to $87.0 \%$, the lowest proportion of all experimental steps.

\subsection{Aeration/waiting effect}

The mean viability of spermatozoa on the surface of the endophallus immediately following ejaculation was $94.8 \%$ (step 4). The mean spermatozoa viability in the semen ejaculated in buffer (94.9\%; step 8) was not found to differ significantly from that in the ejaculate on the fully everted endophallus. This demonstrates that the open ejaculation (unnatural) had no effect on spermatozoa viability. The spermatozoa viability did not also diminish (94.6\%), when the semen was exposed to aeration for 1 min (step 5). Nevertheless, the spermatozoa viability diminished significantly from $94.8 \%$ (step 4) to $91.5 \%$ (step 6) and 89.2\% (step 7), when the semen was exposed to aeration for 2 and $4 \mathrm{~min}$, respectively. One minute-aeration did not affect the spermatozoa viability in ejaculate on the fully everted endophallus, whereas 2- and 4-min aeration resulted in 3.3 and $5.6 \%$ viability loss.

\subsection{Hemolymph effect}

Hemolymph addition to the ejaculate on the fully everted endophallus appeared to have no effect on spermatozoa viability. No significant difference was found between percentage of viable spermatozoa in hemolymph-added ejac- 
ulate (step 9; $93.4 \%$ ) and hemolymph-free ones (step 5; $94.6 \%$ ).

\subsection{Semen collection/syringe tip effect}

The mean spermatozoa viability in ejaculate on the surface of fully everted endophallus (step 4, $94.8 \%$ ) was significantly higher than both those in single-drone ejaculate (step 10; viability loss, $6.3 \%$ ) and in multiple-drone ejaculates (step 11; loss, $5.1 \%$ ) collected in the tip of the syringe. Thus, the intake of semen into the tip of the syringe diminished the viability of spermatozoa. No significant difference in spermatozoa viability was found between single (step 10) and multiple-drone semen collected in the glass tip of the syringe (step 11).

\section{DISCUSSION}

Up to now, several authors have reported data on spermatozoa viability in honeybee drones representing great variation, measured by fluorescent staining technique combined with microscopy (Collins and Donoghue 1999; Collins and Pettis 2001; Collins 2003, 2004; Lodesani et al. 2004; Burley et al. 2008; Gençer and Kahya 2011a; Bieńkowska et al. 2011; Wegener et al. 2012; Czekoňska et al. 2013a, b; Stürup et al. 2013) or with flow cytometry (Rzymski et al. 2012; Tofilski et al. 2012; Paynter et al. 2014). Our finding that the spermatozoa viability in seminal vesicles is higher than that in ejaculate collected into the syringe tip is in agreement with the finding of Collins (2004).

We confirmed in the present investigation that the drones have higher proportion of live spermatozoa (98.1\%) in their seminal vesicles. But, unexpectedly, both the mean spermatozoa viability in the ejaculates of drones $(94.8 \%)$ and in the lateral oviducts of naturally mated queens $(88.7 \%)$ were lower.

Our present results demonstrated that spermatozoa viability in drones and queens diminished within short time during natural and instrumental insemination. The percentage of live spermatozoa in the lateral oviducts of queens returning from mating flight was significantly lower (about $10 \%$ ) than in the intact seminal vesicles of drones. The questions are what causes spermatozoa viability loss and at which step(s) spermatozoa viability loss occurs during natural and instrumental insemination. We designed this step-by-step study to determine the causes of spermatozoa viability loss. To our knowledge, this is the first report, which addresses the issue of spermatozoa viability loss during natural and instrumental insemination.

Our data demonstrated that the percentage of viable spermatozoa in the bulb of the partly everted endophallus was similar to that in the seminal vesicles. Thus, spermatozoa viability did not decrease during partial eversion. But, spermatozoa viability in the ejaculate decreased to $94.8 \%$, when the full eversion of endophallus occurred. At that step, there was not any other known potential factor causing viability loss except the increased pressure during eversion. The pressure effect was confirmed by applying manual pressure on the partly everted endophallus without permitting the full eversion (step 12; spermatozoa viability, $87.0 \%$ ).

In natural mating process, subsequent drones inject their semen directly into the vagina and the lateral oviducts of the queen (Koeniger et al. 1979; Woyke 2011). Therefore, the ejaculates do not expose to air. However, during semen collection for instrumental insemination, the ejaculate on the surface of fully everted endophallus is exposed to air until collecting it into the tip of the syringe. We tested whether spermatozoa viability loss occurred due to air contact. Our data demonstrated that spermatozoa viability did not diminish, when the ejaculate was exposed to air for $1 \mathrm{~min}$. However, longer aeration decreased spermatozoa viability (aeration less than $1 \mathrm{~min}, 94.8 \%$; $1 \mathrm{~min}, 94.6 \%$; $2 \mathrm{~min}, 91.5 \%$; and $4 \mathrm{~min}$, $89.2 \%$ ). Time-dependent viability loss in the ejaculate may result from coagulation of mucus and evaporation of seminal fluid in the air. We, therefore, simulated natural mating conditions during the eversion of the endophallus to detect 
air exposure effect by preventing drones from ejaculating in the air (step 8). The results indicated that open ejaculation without aeration had no effect on spermatozoa viability.

Another possible factor that was tested is hemolymph contamination during the eversion of the endophallus. During semen collection for instrumental insemination, some very active drones may evert so violently that the endophallus explodes. Collecting semen from the exploded endophallus is not suggested due to the risk of hemolymph contamination to the ejaculate. There is, however, no precise evidence on the harmful effect of hemolymph on the ejaculate. Our results demonstrated that hemolymph contamination during the eversion of the endophallus did not diminish the viability of spermatozoa. We can conclude that hemolymph contamination during the eversion of the endophallus has no any harmful effect on spermatozoa in a short time. However, we do not know whether hemolymph contamination affects spermatozoa migration process, when the queens are inseminated with hemolymph contaminated semen. Based on this finding, therefore, we cannot propose to inseminate queens with semen contaminated with hemolymph.

The results indicated that the decrease in spermatozoa viability occurred during the second stage of eversion (viability loss, $3.3 \%$ ), and during the injection of semen into the lateral oviducts (viability loss, $6.1 \%$ ). The acting factor in spermatozoa viability loss was the increased pressure. During natural mating, the percentage of live spermatozoa decreases due to the pressure during the full eversion of the endophallus (sperm viability, $94.8 \%$ ) and afterward, due to the pressure required to inject the semen into the lateral oviducts mostly filled already with semen from previous drones (sperm viability, $88.7 \%$ ).

The queen mates naturally with an average of about 10 drones. Thus, the semen of the next drone presses also the semen of previous drone. Hence, during 10 matings, the semen of the first drone is pressed 10 times. During each succeeding mating, higher pressure must be required to inject the semen into the oviducts, because the increased volume of semen present already in the oviducts resists more and more during the injection of next semen. The pressure on semen inside the bulb is the same during eversion of endophallus in natural mating as well as during manually provoked eversion of endophallus for semen collection in instrumental insemination. However, undoubtedly, after eversion of the endophallus, the pressure required to inject the subsequent semen into semen-filled oviducts must be higher (viability loss, $6.1 \%$ ) than to flow out on the surface of the endophallus (viability loss, $3.3 \%$ ) during natural eversion as well as during manually provoked eversion.

Gençer and Kahya (2011b) reported that there was no significant difference between the viability of spermatozoa in the lateral oviducts of the queens $4 \mathrm{~h}$ after instrumental insemination $(88.6 \%)$ and $4 \mathrm{~h}$ after natural mating $(87.6 \%)$. They suggested that the viability of spermatozoa in the lateral oviducts of naturally mated and instrumentally inseminated queens might decrease with time while spermatozoa migrate into the spermatheca. However, in this study, we did not find evidence for a decrease in spermatozoa viability over time; the viability of spermatozoa in the lateral oviducts of the queens immediately after mating $(88.7 \%$ ) was similar to that of the queens $4 \mathrm{~h}$ after mating (87.6 \%; Gençer and Kahya 2011b).

The semen collected into the tip of syringe is injected slowly into the lateral oviducts of the queens with less pressure during instrumental insemination compared to sequential convulsive ejaculations of drones in natural mating. Therefore, semen collected in the tip of syringe may not be exposed to much pressure during injecting into the lateral oviducts. The effect of pressure is expected to be similar both in manually provoked eversion and in natural eversion during copulation. But, handling of semen is a significant factor affecting spermatozoa viability. Sucking semen up and down into the syringe tip during semen collection causes spermatozoa damage (Collins 2004). Our data demonstrated that collecting the semen into 
the glass tip of syringe caused 5-6\% spermatozoa viability loss. We determined $88.7 \%$ viable spermatozoa in the lateral oviducts of the queens as soon as they returned from mating. This was similar to the viability of spermatozoa in the lateral oviducts of instrumentally inseminated queens $(88.6 \%$ ) reported by Gençer and Kahya (2011b). According to these findings, spermatozoa damage during semen collection procedure seems to be compensated by less pressure effect during injecting semen into lateral oviducts in instrumental insemination.

The published data show that the viability of spermatozoa collected into the tip of syringe is generally lower (under $91 \%$ ) than that of spermatozoa in seminal vesicles $(98 \%)$. Our data demonstrated that inevitable natural viability loss occurs during eversion of endophallus due to the pressure effect. Collecting ejaculate into the syringe tip is another factor causing spermatozoa death. Many papers have been published on spermatozoa viability in honeybee drones without considering the effect of eversion (pressure effect). We, therefore, would like to point out that spermatozoa viability values estimated from ejaculate and semen collected into the syringe tip are always lower than spermatozoa viability values estimated from seminal vesicles. We also would like to stress that the pressure effect has to be considered in spermatozoa viability studies. Otherwise, it will not be correct to compare spermatozoa viability values obtained from ejaculate or syringe tip from one study with spermatozoa viability values obtained from seminal vesicles from another study. Our method explained in step 3 will help researchers estimate spermatozoa viability in drones without applying laborious dissection protocol, which is a key measure in appreciating the reproductive success of drones. We also offer a novel way of obtaining plenty of hemolymph from drones (step 9).

\section{ACKNOWLEDGMENTS}

We thank two anonymous reviewers for their constructive comments and suggestions. We also thank Siamak Hamednia and Burak Kiziltepe for their help with field and laboratory work.
Pourquoi la viabilité des spermatozoïdes diminue chez l'abeille, Apis mellifera, très rapidement après un accouplement ou après la préparation pour une insémination artificielle

Mâle / reine / éversion de l'endophallus / insémination artificielle / spermatozoïdes

Warum die Lebensfähigkeit der Spermatozoen von Honigbienen (Apis mellifera) innerhalb kurzer Zeit während der natürlichen Begattung und der Präparation für die künstliche Besamung abnimmt

Drohn / Königin / Ausstïlpen des Endophallus / künstliche Besamung / Sparmatozoenlebensfähigkeit

\section{REFERENCES}

Baer, B., Zareie, R., Paynter, E., Poland, V., Millar, A.H. (2012) Seminal fluid proteins differ in abundance between genetic lineages of honeybees. J. Proteomics 75, 5646-5653

Bieńkowska, M., Panasiuk, B., Węgrzynowicz, P., Gerula, D. (2011) The effect of different thermal conditions on drone semen quality and number of spermatozoa entering the spermatheca of queen bee. J. Apic. Sci. 55, 161-168

Burley, L.M., Fell, R.D., Saacke, R.G. (2008) Survival of honey bee (Hymenoptera. Apidae) spermatozoa incubated at room temperature from drones exposed to miticides. J. Econ. Entomol. 101, 1081-1087

Collins, A.M. (2000) Survival of honey bee (Hymenoptera: Apidae) spermatozoa stored at above-freezing temperatures. J. Econ. Entomol. 93, 421-429

Collins, A.M. (2003) A scientific note on the effect of centrifugation on pooled honey bee semen. Apidologie 34, 469-470

Collins, A.M. (2004) Sources of variation in the viability of honey bee, Apis mellifera L., semen collected for artificial insemination. Invertebr. Reprod. Dev. 45, 231-237

Collins, A.M., Donoghue, A.M. (1999) Viability assessment of honey bee, Apis mellifera, sperm using dual florescent staining. Theriogenology 51, 1513-1523

Collins, A.M., Pettis, J.S. (2001) Effect of varroa infestation on semen quality. Am. Bee J. 141, 590593

Czekońska, K., Chuda-Mickiewicz, B., Chorbiński, P. (2013a) The effect of brood incubation temperature on the reproductive value of honey bee (Apis mellifera) drones. J. Apic. Res. 52, 96-105

Czekońska, K., Chuda-Mickiewicz, B., Chorbiński, P. (2013b) The influence of honey bee (Apis mellifera) drone age on volume of semen and viability of spermatozoa. J. Apic. Sci. 57, 61-66 
Dade, H. A. (1977) Anatomy and dissection of the honeybee. International Bee Research Association; London.

den Boer, S.P.A., Boomsma, J.J., Baer, B. (2009) Honey bee males and queens use glandular secretions to enhance sperm viability before and after storage. J. Insect Physiol. 55, 538-543

Gençer, H.V., Kahya, Y. (2011a) Are sperm traits of drones (Apis mellifera L.) from laying worker colonies noteworthy? J. Apic. Res. 50, 130-137

Gençer, H.V., Kahya, Y. (2011b) The viability of sperm in lateral oviducts and spermathecae of instrumentally inseminated and naturally mated honey bee (Apis mellifera L.) queens. J. Apic. Res. 50, 190-194

Holman, L. (2009) Sperm viability staining in ecology and evolution: potential pitfalls. Behav. Ecol. and Sociobiol. 63, 1679-1688

Hopkins, B.K., Herr, C. (2010) Factors affecting the successful cryopreservation of honey bee (Apis mellifera) spermatozoa. Apidologie 41, 548-556

Hunter, F.M., Birkhead, T.R. (2002) Sperm viability and sperm competition in insects. Curr. Biol. 12, 121123

Imhoof, M. (2012) More than honey. Film Against Gravity

Koeniger, G. (1986) Mating sign and multiple mating in the honeybee. Bee World 67, 141-150

Koeniger, G. (n.d.) Mehrfachpaarung der Bienenkönigin. Ein Film des Institut für Bienenkunde, Oberursel, Germany.

Koeniger, N., Koeniger, G. (1991) An evolutionary approach to mating behavior and drone copulatory organs in Apis. Apidologie 22, 581-590

Koeniger, G., Koeniger, N., Fabritius, M. (1979) Some detailed observations of mating in the honey bee. Bee World 60, 53-57

Laidlaw Jr., H.H., Page Jr., R.E. (1997) Queen rearing and bee breeding. Wicwas Press, Cheshire

Locke, S.J., Peng, Y.S. (1993) The effects of drone age, semen storage, and contamination on semen quality in the honey bee (Apis mellifera). Physiol. Entomol. 18, 144-148

Lodesani, M., Balduzzi, D., Galli, A. (2004) Functional characterization of semen in honeybee queen $(A . m$. ligustica S.) spermatheca and the efficiency of diluted semen technique in instrumental insemination. Ital. J. of Anim Sci. 3, 385-392

Moritz, R.F.A. (1984) The effect of different diluents on insemination success in the honeybee using mixed semen. J. Apic. Res. 23, 164-167

Page Jr., R.E. (1986) Sperm utilization in social insects. Annu. Rev. Entomol. 31, 297-320

Paynter, E., Baer-Imhoof, B., Linden, M., Lee-Pullen, T., Heel, K., Rigby, P., Baer, B. (2014) Flow cytometry as a rapid and reliable method to quantify sperm viability in the honeybee Apis mellifera. Cytometry Part A . 85, 463-472

Peer, D.F. (1956) Multiple mating of queen honey bees. J. Econ. Entomol. 49, 741-743

Ruttner, F. (1988) Breeding techniques and selection for breeding of the honeybee. British Isles of Bee Breeders' Association, Derby

Ruttner, F., Koeniger, G. (1971) Die Füllung der Spermatheca der Bienenkönigin. Aktive Wandering oder Passiver Transport der Spermatozoen? Z. Vergl Physiolgie 72, 411-422

Rzymski, P., Langowska, A., Fliszkiewicz, M., Poniedziałek, B., Karczewski, J., Wiktorowicz, K. (2012) Flow cytometry as an estimation tool for honey bee sperm viability. Theriogenology 77, 1642-1647

Schlüns, H., Koeniger, G., Koeniger, N., Moritz, R.F.A. (2004) Sperm utilization pattern in the honeybee (Apis mellifera). Behav. Ecol. Sociobiol. 56, 458463

Stürup, M., Baer-Imhoof, B., Nash, D.R., Boomsma, J.J., Baer, B. (2013) When every sperm counts: factors affecting male fertility in the honeybee Apis mellifera. Behav. Ecol. 24, 1192-1198

Taber, S. (1954) The frequency of multiple mating of queen honey bees. J. Econ. Entomol. 47, 995998

Tofilski, A., Chuda-Mickiewicz, B., Czekońska, K., Chorbiński, P. (2012) Flow cytometry evidence about sperm competition in honey bee (Apis mellifera). Apidologie 43, 63-70

Verma, L.R. (1974) Honeybee spermatozoa and their survival in the queen's spermatheca. Bee World 55, 53-61

Wegener, J., Bienefeld, K. (2012) Toxicity of cryoprotectants to honey bee semen and queens. Theriogenology 77, 600-607

Wegener, J., May, T., Knollmann, U., Kamp, G., Müller, K., Bienefeld, K. (2012) In vivo validation of in vitro quality tests for cryopreserved honey bee semen. Cryobiol. 65, 126-131

Woyke, J. (1956) Anatomo-physiological changes in queen bees returning from mating flights, and the process of multiple mating. Bull. Acad. Polon. Sci 4, 81-87. online; jerzy_woyke.users.sggw.pl/ 1956_anphymat.pdf

Woyke, J. (1962) Natural and artificial insemination of queen honeybees. Bee World 43, 21-25

Woyke, J. (1983) Dynamics of entry of spermatozoa into the spermatheca of instrumentally inseminated queen honeybees. J. Apic. Res. 22, 150154

Woyke, J. (1988) A mathematical model for the dynamics of spermatozoa entry into the spermathecae of instrumentally inseminated queen honeybees. J. Apic. Res. 27, 122-125 
Woyke, J. (2008) Why the eversion of endophallus of honey bee drone stops at the partly everted stage and significance of this. Apidologie 39, $627-636$

Woyke, J. (2010) Three substances ejected by Apis mellifera drones during endophallus eversion as well as during natural matings with queen bees. Apidologie 41, 613-621

Woyke, J. (2011) The mating sign of queen bees originates from two drones and the process of multiple mating in honey bees. J. Apic. Res. 50, 272-283 